\title{
Dynamics of thermoluminescence spectra of impurity- helium condensates containing stabilized nitrogen and oxygen atoms
}

\author{
V.V. Khmelenko ${ }^{1}$, I.N. Krushinskaya ${ }^{2}$, R.E. Boltnev ${ }^{2}$, I.B. Bykhalo ${ }^{2}$, A.A. Pelmenev², \\ and D.M. Lee ${ }^{1}$ \\ ${ }^{1}$ Department of Physics and Astronomy, Texas A\&M University, College Station, TX 77843, USA \\ ${ }^{2}$ Branch of Institute of Energy Problems of Chemical Physics RAS, Chernogolovka 142432, Russia \\ E-mail: boltnev@binep.ac.ru; boltnev@gmail.com
}

Received March 12, 2012

\begin{abstract}
The results of investigations of thermoluminescence dynamics during destruction of neon-helium and krypton-helium condensates containing stabilized nitrogen and oxygen atoms are presented. Spectra of the thermoluminescence of a krypton-helium condensate contained bands of $\mathrm{N}$ and $\mathrm{O}$ atoms and $\mathrm{NO}$ molecules. The intensities of the bands in these spectra were found to increase simultaneously during destruction processes in the temperature range $1.5-15 \mathrm{~K}$. Observation of the NO molecules provides clear evidence for chemical reactions in the nanoclusters comprising the sample at low temperatures. Destruction of neon-helium samples occurred in two stages. During the first stage the $\alpha$-group of $\mathrm{N}$ atoms surrounded by $\mathrm{Ne}$ and $\mathrm{N}_{2}$ molecules dominated the spectra. During the second stage, the spectra contained intense bands of $\mathrm{N}$ and $\mathrm{O}$ atoms stabilized in a molecular nitrogen matrix. The unusual characteristics of the thermoluminescence spectra were observed, and their changes were explained in terms of the shell structure of impurity nanoclusters which comprised the impurity-helium condensates.
\end{abstract}

PACS: 67.80.-s Quantum solids;

78.60.-b Other luminescence and radiative recombination;

36.40.Mr Spectroscopy and geometrical structure of clusters.

Keywords: thermoluminescence spectra, nanoclusters, impurity-helium condensates.

\section{Introduction}

Impurity-helium condensates (IHCs) are of great interest as new porous nanostructures possessing unique properties, promising for basic sciences as well as for practical applications [1]. That is why understanding the characteristic features of formation, stability and destruction of IHCs is significant.

The characteristic size of the constituent building blocks of IHCs, impurity nanoclusters $(\sim 5 \mathrm{~nm})$ and the density of impurity atoms $\left(\sim 10^{19}-10^{21} \mathrm{~cm}^{-3}\right)$ have been determined from $\mathrm{x}$-ray scattering experiments $[2,3]$, as well as the internal surface area of IHCs $\left(\sim 50 \mathrm{~m}^{2} / \mathrm{cm}^{3}\right)$ [4]. Stabilization of radicals (for example, atomic hydrogen, deuterium or nitrogen) occurs mainly on the surface of impurity nanoclusters separated each from other by adsorbed helium shells [5]. ESR spectroscopy studies of $\mathrm{H}$ and $\mathrm{D}$ atoms stabilized in krypton-helium condensates have revealed very high surface densities of atoms, up to
$10^{14}$ deuterium atoms $/ \mathrm{cm}^{2}[5,6]$. The highest average concentrations of nitrogen atoms obtained in nitrogen-helium samples are $5 \cdot 10^{19} \mathrm{~cm}^{-3}$ [7]. The values of the local concentrations of nitrogen atoms estimated from the ESR line widths resulting from dipole-dipole broadening are as high as $8 \cdot 10^{20} \mathrm{~cm}^{-3}$. Systems containing such high concentrations of stabilized radicals are of great interest for studying spin interactions and to search for new materials with high energy content. Therefore investigations of the temperature stability and destruction mechanisms of such systems are of great importance. Warming up the IHC sample when removed from bulk liquid helium initiates evaporation of helium layers, giving rise to direct contact between neighboring cluster surfaces, accompanied by recombination of the stabilized species. Such behavior could be promising for cryosynthesis of new chemical compounds. The first results demonstrating an occurrence of chemical reactions during destructions of IHC samples were obtained from the thermoluminescence studies $[8,9]$. Recombination of radi- 
cals occurs mainly on the cluster surfaces. That is a crucial difference in comparison to earlier studies of radicals trapped in matrices [10]. Warming up the IHC sample after removal of liquid helium causes growth of impurity clusters $[2,11,12]$. The possibility of fast detection of luminescence spectra gives optical spectroscopy an advantage as compared with CW ESR and x-ray diffraction techniques. This possibility allows us to study the dynamics of various processes during warming up and destruction of IHC samples.

Luminescence investigations of cryosystems containing stabilized atoms have attracted the attention of scientists for almost one hundred years [13-15]. Intense studies of radicals trapped in matrices at helium temperatures were initiated in the middle of the last century [10]. The cryomatrix luminescence is one of the most convenient means of stabilized radical detection. The first studies of the thermoluminescence of solid matrices of molecular nitrogen containing stabilized nitrogen atoms revealed the $\alpha$ - and $\alpha$ 'groups of atomic nitrogen [16]. The thermoluminescence was observed within the temperature range $4.2-35 \mathrm{~K}$. The NO bands were observed in the thermoluminescence studies upon warming matrices of rare gases and molecular nitrogen doped with $\mathrm{N}$ and $\mathrm{O}$ atoms from $1.2 \mathrm{~K}$ to $40 \mathrm{~K}$ [17-20]. For example, $M-$ and $\beta$-bands corresponding to the transitions $a^{4} \Pi-X^{2} \Pi$ and $B^{2} \Pi-X^{2} \Pi$ of NO molecules were detected upon the warming of Ar matrices, while M-bands were only observed in the thermoluminescence spectra of $\mathrm{Kr}$ matrices [19]. Production of excited NO molecule were explained by recombination of $\mathrm{N}\left({ }^{4} \mathrm{~S}\right)$ and $\mathrm{O}\left({ }^{3} \mathrm{P}\right)$ in krypton and argon matrices within the temperature range $15-23 \mathrm{~K}$.

The first thermoluminescence studies of IHC samples were focused on the $\alpha$-group emission detection of nitrogen atoms [21]. It had been established that increases in temperatures as small as $50 \mathrm{mK}$ caused an onset of emission from IHC samples even when they were immersed in HeII [22]. The emission maxima have been observed at temperatures values 2.17 and $3.5 \mathrm{~K}$ when the sample was in liquid helium [21]. The IHC samples were destroyed after their removal from bulk LHe, and their final destructions was explosive. The first thermoluminescence studies during IHC destruction was carried out over a wide spectral range in 1999 [23]. The intense thermoluminescence of the $\alpha$-group of $\mathrm{N}$ atoms as well as the $\beta$-group of $\mathrm{O}$ atoms was observed within the temperature range of 1.8-14 K from all the IHC samples containing stabilized $\mathrm{N}$ and $\mathrm{O}$ atoms. The weak emissions of $\alpha^{\prime}$ - and $\beta^{\prime}$-groups were also detected in the destruction spectra of nitrogen-helium samples. The intense M-bands of NO molecules corresponding to the $a^{4} \Pi, v^{\prime}=0-X^{2} \Pi, v^{\prime \prime}$ transitions were observed upon destructions of argon-helium and kryptonhelium samples. The bands $\left(\mathrm{E}^{1} \Sigma, v^{\prime}=0-\mathrm{B}^{1} \Sigma, v^{\prime \prime}\right)$ of excimer molecules $\mathrm{XeO}$ had been observed during destruction of xenon-helium sample. Later these results of ther- moluminescence studies of nitrogen-helium condensates were confirmed $[24,25]$. Moreover, in these later studies the $\delta$-group, corresponding to $\mathrm{N}\left({ }^{2} \mathrm{P}-{ }^{2} \mathrm{D}\right)$ transition and Vegard-Kaplan bands of molecular nitrogen, were also detected.

IHC samples prepared by condensation of nitrogenneon-helium and nitrogen-krypton-helium gas mixtures in superfluid helium bulk have also been studied in our work. In comparison to the earlier studies of integrated over time thermoluminescence spectra of IHC samples [23], the observed emission spectral changes allowed us to determine the precise dynamics during destruction of the samples under study. The thermoluminescence spectra accompanying destruction of $\mathrm{N}-\mathrm{N}_{2}-\mathrm{Ne}-\mathrm{He}$ samples mainly came from metastable oxygen and nitrogen atoms. The atoms were excited by effective energy transfer within the molecular nitrogen matrix from excited $\mathrm{N}_{2}$ molecules formed by recombination of $\mathrm{N}$ atoms. Destruction of $\mathrm{N}-\mathrm{N}_{2}-\mathrm{Kr}-\mathrm{He}$ samples was accompanied mainly by emission of metastable $\mathrm{O}$ atoms and NO molecules. Dynamics of the detected thermoluminescence spectra reveals the pathways and the relaxation mechanisms of energy stored by radicals stabilized in the IHC samples studied.

\section{Experimental setup}

The experimental technique of IHC sample preparation has been described elsewhere $[9,26]$. The technique was first developed in 1974 [27]. It is based on the injection of a helium gas jet containing impurity particles $\left(\mathrm{Im}=\mathrm{N}, \mathrm{N}_{2}, \mathrm{H}\right.$, $\mathrm{H}_{2}, \mathrm{Ne}, \mathrm{Ar}, \mathrm{Kr}$ etc.) into bulk HeII. The gas mixture enters a helium bath region (Fig. 1) from a quartz capillary cooled with liquid nitrogen (pos. 1 on Fig. 1). The lower portion of the capillary is surrounded by electrodes to produce a radiofrequency (rf) discharge $(f=40 \mathrm{MHz}, P=$ $=60 \mathrm{~W}$ ). The oxygen content in the gas mixtures is mainly a result of the contamination of helium gas. We em-

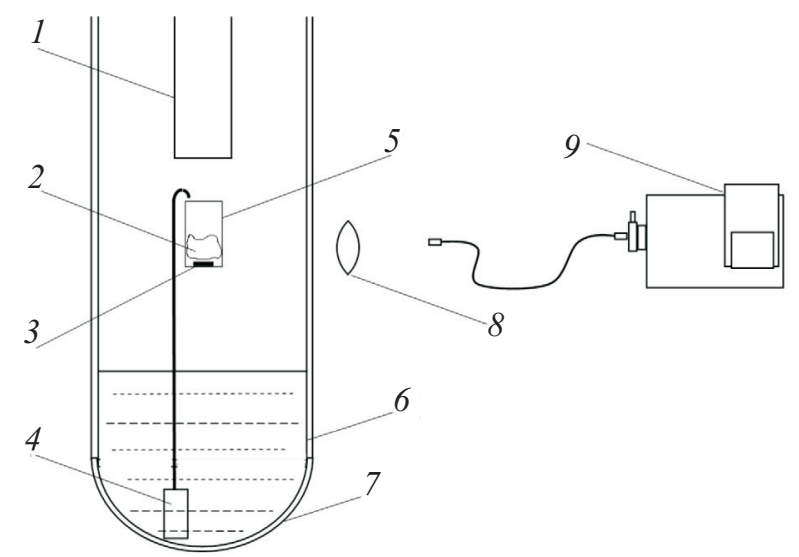

Fig. 1. Experimental setup: source of atoms (1); IHC sample (2); thermometer (3); fountain pump (4); glass beaker (5); helium dewar (6); nitrogen dewar (7); condensing lens (8); spectrometer with fiber (9). 
ploy helium gas with an oxygen content of $\sim 10 \mathrm{ppm}$. The typical conditions during sample preparation were as follows: the impurity admixture, $[\mathrm{Im}] /[\mathrm{He}] \sim 0.5-4 \%$, the gas jet flux $(5-7) \cdot 10^{19} \mathrm{~s}^{-1}$, the temperature $1.5 \mathrm{~K}$, and the duration of the sample condensation $\approx 1000 \mathrm{~s}$. A jet consisting of a mixture of helium and impurity gases was directed onto the surface of superfluid helium (HeII) contained in a glass beaker (pos. 5 on Fig. 1) placed below the source at a distance of $20-25 \mathrm{~mm}$. The steady state level of HeII in the beaker was maintained by a fountain pump situated in the main liquid helium bath.

Sample destruction was caused by warming up, as stimulated by increasing the pressure and by ceasing the pumping of HeII into the beaker via the fountain pump. Green emission, the so-called, $\alpha$-group, was initiated by warming the samples containing stabilized $\mathrm{N}$ atoms. All the samples under study were destroyed at temperatures lower than $15 \mathrm{~K}$. The origin of thermoluminescence in IHCs was studied earlier $[8,23]$. At the sample temperatures above $4 \mathrm{~K}$ (there was no liquid helium in the beaker) one can see spontaneous flashes with the most intense ones having been observed upon final sample destruction (sublimation).

Use of a fast detection system with better spectral response and higher optical resolution is the main improvement in the present work as compared with the earlier work. The light emission from the sample passed through optical slits in both the helium and the nitrogen glass dewars and was collected by a lens focusing on the end of the optical fiber which was, in turn, attached to the entrance slit of the spectrometer (Ocean Optics HR2000+). The spectrometer allows spectrum capture rates up to 1000 full spectra/s (within the spectral range of 200-1100 nm). The real registration time for spectra was either $0.4 \mathrm{~s}$ or $1 \mathrm{~s}$ and depended on the luminescence intensity. The glass dewars and beaker restricted the accessible spectral range to $325-1100 \mathrm{~nm}$. The optical resolution of the spectrometer was of order $1.3 \mathrm{~nm}$ (FWHM).

The spectrometer was recalibrated before the experimental run. We used 43 spectral lines of $\mathrm{Zn}, \mathrm{Pb}, \mathrm{In}, \mathrm{Zn}$ and $\mathrm{Cd}$ atoms over the spectral range $300-900 \mathrm{~nm}$. The recalibration results were applied to determine new wavelength calibration coefficients.

\section{Experimental results}

\subsection{Samples prepared from a gas mixture with the composition $\left[\mathrm{N}_{2}\right]:[\mathrm{Ne}]:[\mathrm{He}]=1: 20: 500$}

Sample preparation spectra. Accumulation of IHC samples containing stabilized $\mathrm{N}$ and $\mathrm{O}$ atoms is accompanied by intense luminescence. By focusing on the gas jet or the sample in HeII, we were able to detect the spectra of excited particles in the gas phase or in condensing samples. The integral (along the whole jet length) spectrum of a gas mixture with the composition $\left[\mathrm{N}_{2}\right]:[\mathrm{Ne}]:[\mathrm{He}]=1: 20: 500$ after passing through the rf discharge region is shown in Fig. 2. The $\alpha$ - and $\beta$ - groups corresponding to the transitions $\mathrm{N}\left({ }^{2} \mathrm{D} \rightarrow{ }^{4} \mathrm{~S}\right)$ and $\mathrm{O}\left({ }^{1} \mathrm{~S} \rightarrow{ }^{1} \mathrm{D}\right)$ dominate the spectrum, as compared with lines of $\mathrm{Ne}$ and $\mathrm{He}$ atoms or the bands of $1^{+}$

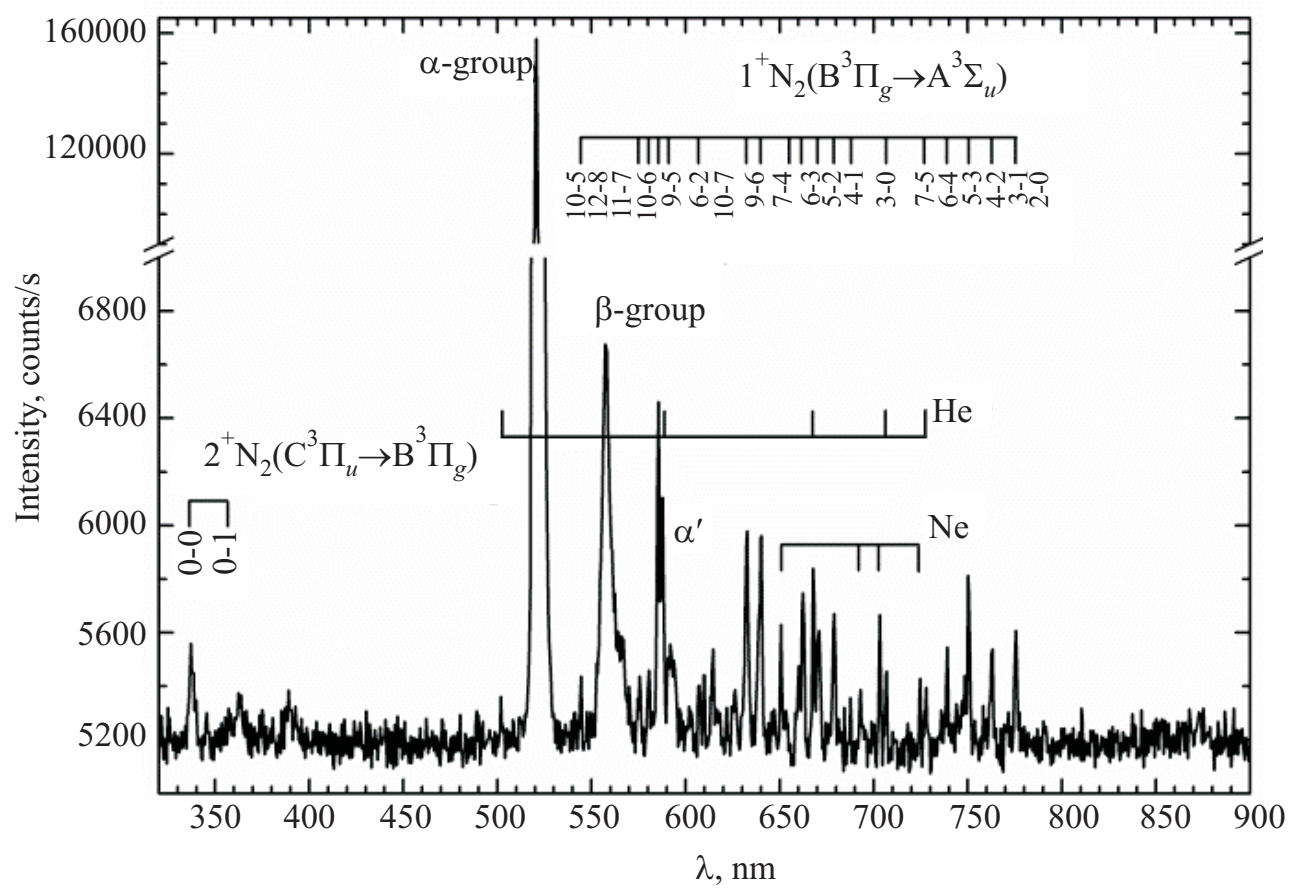

Fig. 2. The integrated luminescence spectrum of the gas jet (with composition $\left[\mathrm{N}_{2}\right]:[\mathrm{Ne}]:[\mathrm{He}]=1: 20: 500$ ) after passing through the rf discharge region during sample accumulation. 
(first positive) and $2^{+}$(second positive) systems of molecular nitrogen related to the transitions $\mathrm{B}^{3} \Pi_{g}-\mathrm{A}^{3} \Sigma_{u}^{+}$and $\mathrm{C}^{3} \Pi_{u}-\mathrm{B}^{3} \Pi_{g}$, respectively. The presence in the spectrum of intense $\alpha$ - and $\beta$-groups provides evidence that the process of impurity particle clustering takes place in the gas jet [24].

Thermoluminescence spectra of neon-helium samples. We stopped pumping HeII into the beaker after sample preparation in order to warm-up the sample. There was a negligible increase in the sample temperature $(0.5-0.8 \mathrm{~K})$ during liquid helium evaporation from the beaker. Following liquid helium evaporation, the warm-up rate increased, and the sample was usually destroyed within 200 s. Sublimation of helium atoms adsorbed on impurity cluster surfaces was a trigger, initiating recombination of the stabilized radicals, which was accompanied both by intense emission and rapidly increasing temperature. Fast acquisition (every 0.4 or $1 \mathrm{~s}$ ) of thermoluminescence spectra allowed us to obtain information on the atom recombination processes and to discern the relaxation channels for energy release in the solid matrices composed of aggregated clusters. The thermoluminescence spectra were studied in two different warming modes, a "fast" mode corresponding to thermal destruction of the sample immediately after preparation and a "delayed" mode which also included aging the sample in bulk HeII for a period of 300-1800 s. In both modes, the sample destruction occurred within a period of 160-200 s, but the spectra detected corresponding to these modes were quite different.
"Fast" sample warm up. The dynamics of thermoluminescence spectra during warming of the sample prepared by condensing the gas mixture $\left[\mathrm{N}_{2}\right]:[\mathrm{Ne}]:[\mathrm{He}]=1: 20: 500$ is presented in Fig. 3. The spectral region 510-580 nm contains the most pronounced and intense features observed in the experiments. One can see continuous luminescence of the $\alpha$-group with two maxima, one at the beginning and the other close to the end of time of the sample destruction. In contrast, the $\beta$-group emission appeared only at final stage of sample destruction and dominated at the end of the sample destruction. Figure 3 illustrates changes of the $\alpha$-group spectra over the entire period of sample destruction.

A sequence of $\alpha$-group spectra with an extended scale detected at different times is shown in Fig. 4. The $\alpha$-group spectra at the beginning of the sample destruction had a maximum at $520 \mathrm{~nm}$ whereas at the end of the sample destruction, peaks were observed at $522 \mathrm{~nm}$. One can also see some intermediate spectra associated with the two peaks at 520 and $522 \mathrm{~nm}$. The $\alpha$-group spectrum evolution reveals the changes in the environment of the emitting $\mathrm{N}$ atoms during sample destruction. Some spectra of the $\alpha$ - and $\beta$-groups showed different intensities but with similar spectrum shapes. This allowed us to make extrapolations for overexposed spectra at the beginning and the end of sample destruction. Some of these extrapolation results are provided in Figs. 3 and 5 (one can see spectral lines with the intensities exceeding the working range of the spectrometer (Ocean Optics HR2000+, 16384 counts/s). Such extrapolations permit an evaluation of the most intense spectral features and to compare the intensities of the $\alpha$ - and $\alpha^{\prime}$-groups.

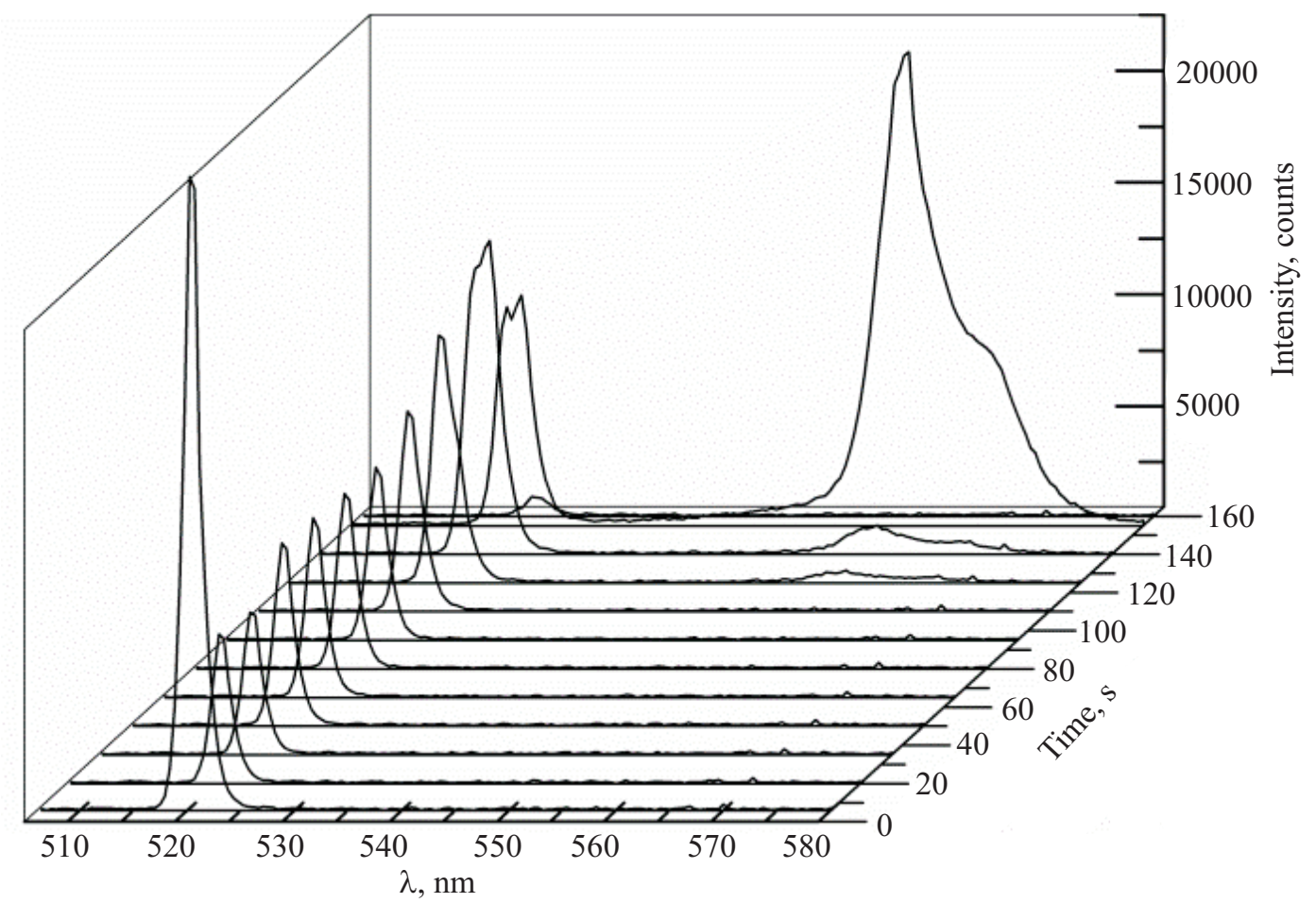

Fig. 3. Dynamics of thermoluminescence spectra during a "fast" warm-up of the sample prepared by condensing a gas mixture $\left[\mathrm{N}_{2}\right]:[\mathrm{Ne}]:[\mathrm{He}]=1: 20: 500$. The $\alpha$-group is centered near $520 \mathrm{~nm}(\mathrm{~N}$ atoms $)$ and the $\beta$-group near $560 \mathrm{~nm}(\mathrm{O}$ atoms). 


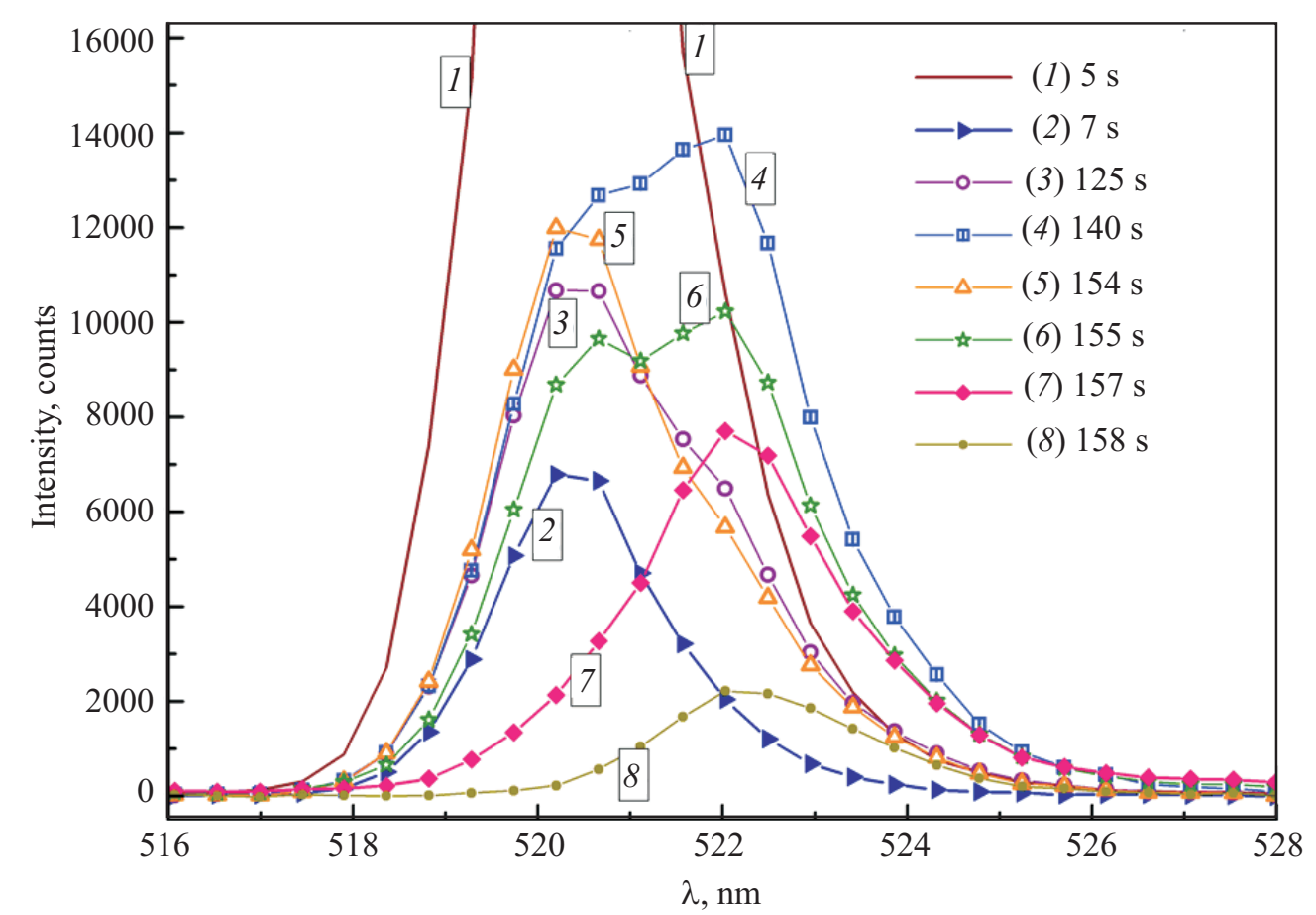

Fig. 4. A sequence of $\alpha$-group spectra detected at different times for a "fast" warm-up of the sample condensed from gas mixture $\left[\mathrm{N}_{2}\right]:[\mathrm{Ne}]:[\mathrm{He}]=1: 20: 500$ (the detection times correspond to the time scale in Fig. 3).

A comparison of the thermoluminescence spectra detected at the beginning and the end of the sample destruction is given in Fig. 5. In addition to the most intense $\alpha$ and $\beta$-groups, at the final stage of sample destruction (Fig. 5,b), one can also see the $\alpha^{\prime}$-, $\delta$ - and $\delta^{\prime \prime}$-groups of $\mathrm{N}$ atoms, the $\beta^{\prime}$ and $\beta^{\prime \prime}$-groups of $\mathrm{O}$ atoms, an unidentified $\gamma$-line, and broad blue bands. The presence of $\alpha^{\prime}-, \beta^{\prime}-, \beta^{\prime \prime}-$ and $\delta^{\prime \prime}$-groups in the spectra indicates that $\mathrm{N}_{2}$ molecules are neighbors of the emitting $\mathrm{N}$ or $\mathrm{O}$ atoms. It is worth noting that the intensity ratio $I_{\alpha} / I_{\alpha^{\prime}}$ was equal to 570 at the beginning, but only 80 at the end. Moreover, the correlation of the red shifted values of the $\alpha$ - and $\alpha^{\prime}$-group

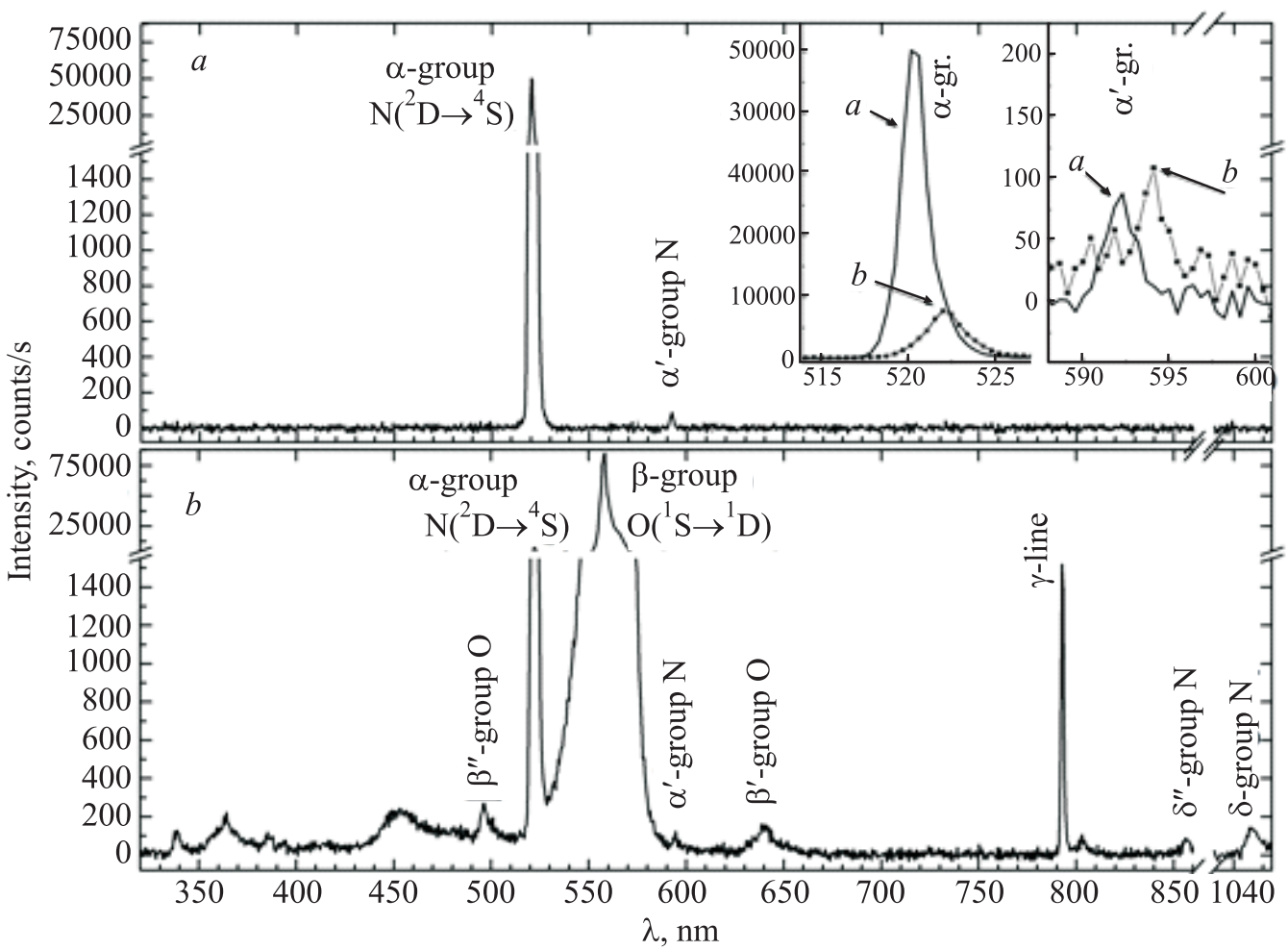

Fig. 5. A comparison of the thermoluminescence spectra detected at the beginning $(a)$ and the end $(b)$ of the "fast" sample destruction. The corresponding spectra of $\alpha$ - and $\alpha^{\prime}$-groups are shown in the insets. 


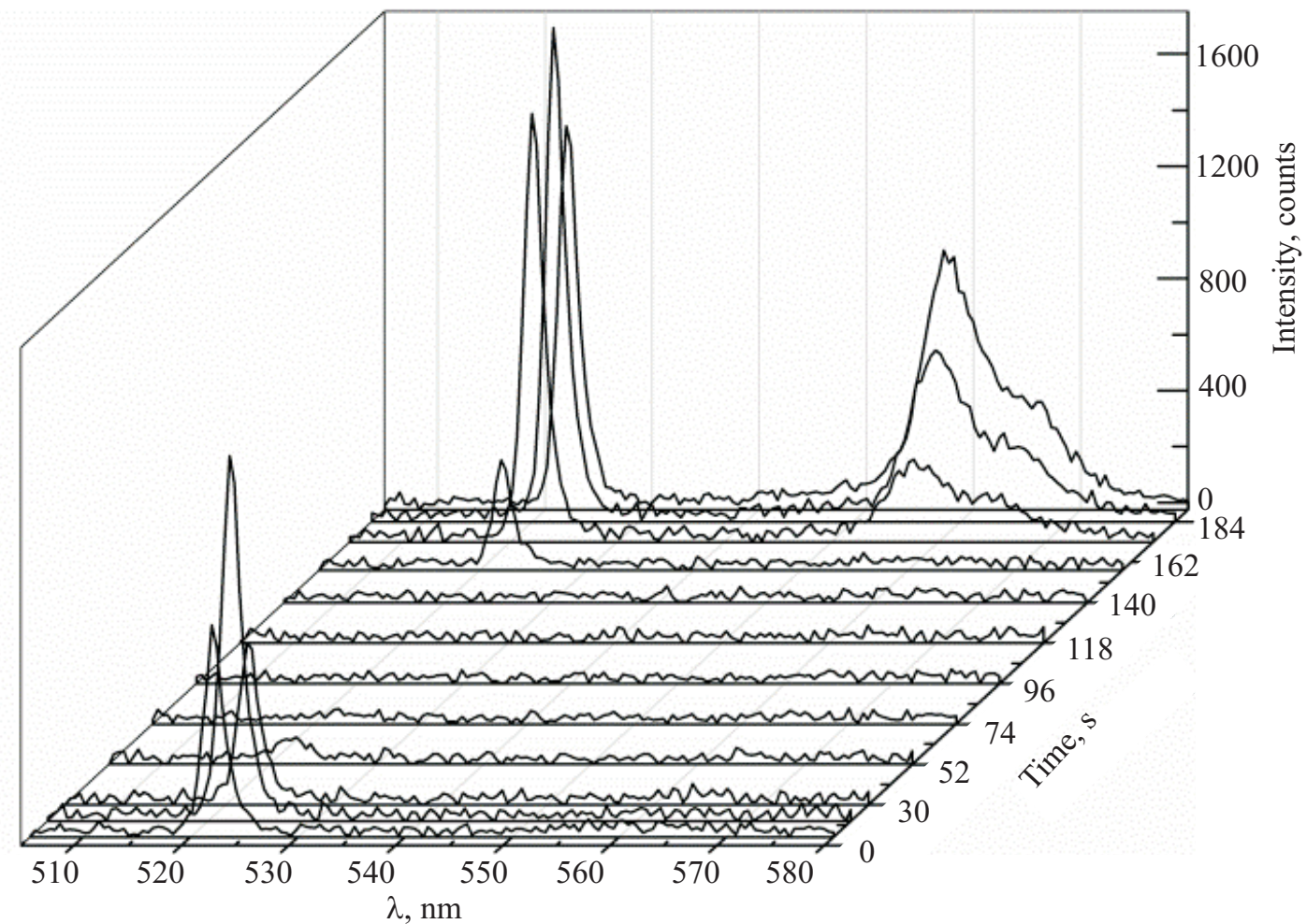

Fig. 6. Dynamics of thermoluminescence spectra during "delayed" warm-up the sample prepared by condensing a gas mixture $\left[\mathrm{N}_{2}\right]:[\mathrm{Ne}]:[\mathrm{He}]=1: 20: 500$.

peaks (Fig. 5,a, insets) by $2 \mathrm{~nm}$ closely corresponds to the spectral shape changes of the $\alpha$-group shown in Fig. 4.

"Delayed" warm up of the sample. The dynamics of thermoluminescence spectra during a "delayed" warm-up of the sample prepared by condensing a gas mixture $\left[\mathrm{N}_{2}\right]:[\mathrm{Ne}]:[\mathrm{He}]=1: 20: 500$ is presented in Fig. 6 . The sam- ple had been stored in bulk HeII for $1800 \mathrm{~s}$ at a temperature below $1.8 \mathrm{~K}$ before being warmed. Two luminescence maxima of the $\alpha$-group intensity at the beginning and the end of the sample destruction along with the $\beta$-group appearing at the final stage of destruction were observed just as for the case of the "fast" warm-up. Nevertheless some

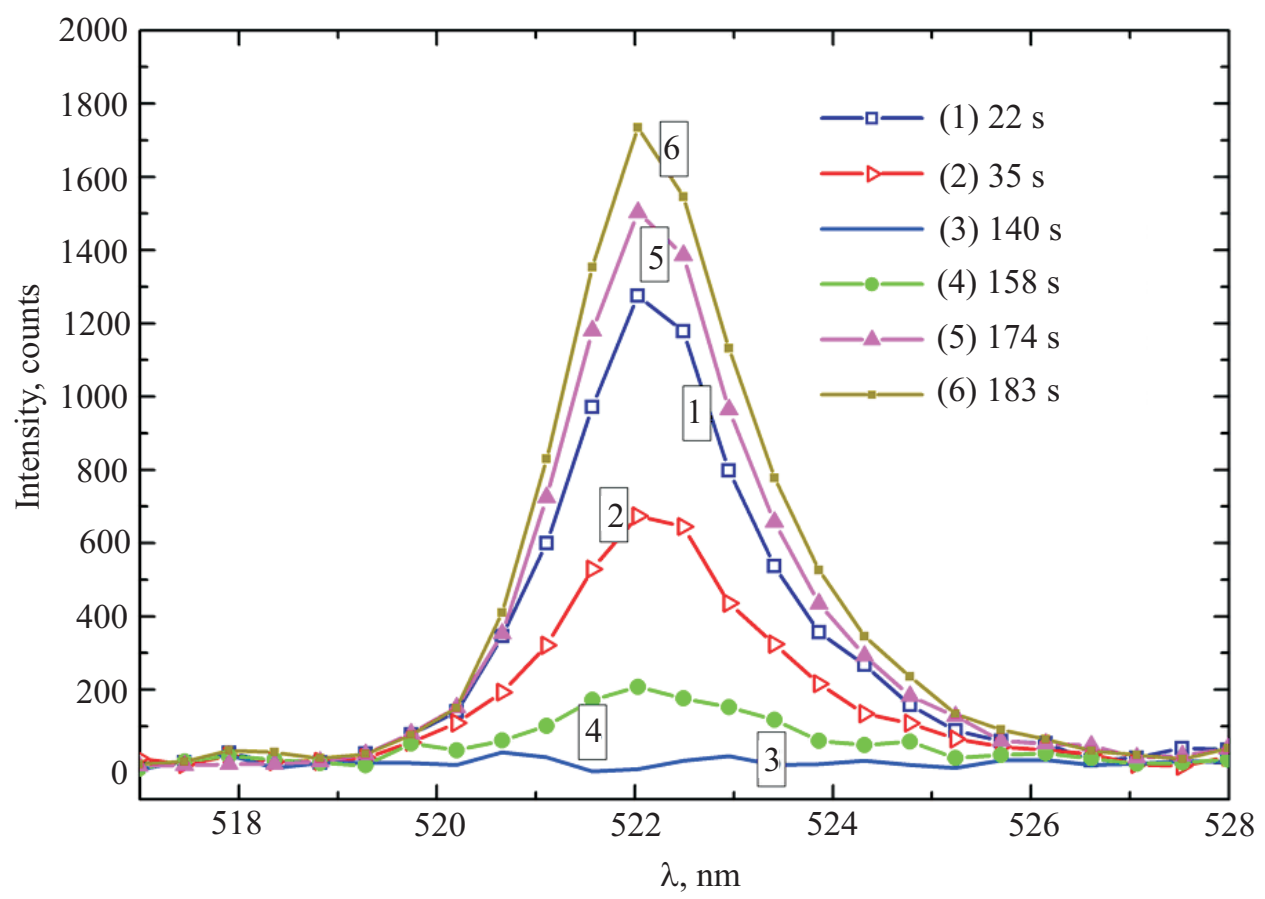

Fig. 7. A sequence of $\alpha$-group spectra detected at different times during the "delayed" warm-up of the sample condensed from gas mixture $\left[\mathrm{N}_{2}\right]:[\mathrm{Ne}]:[\mathrm{He}]=1: 20: 500$ (the detection times correspond to the time scale in Fig. 6). 


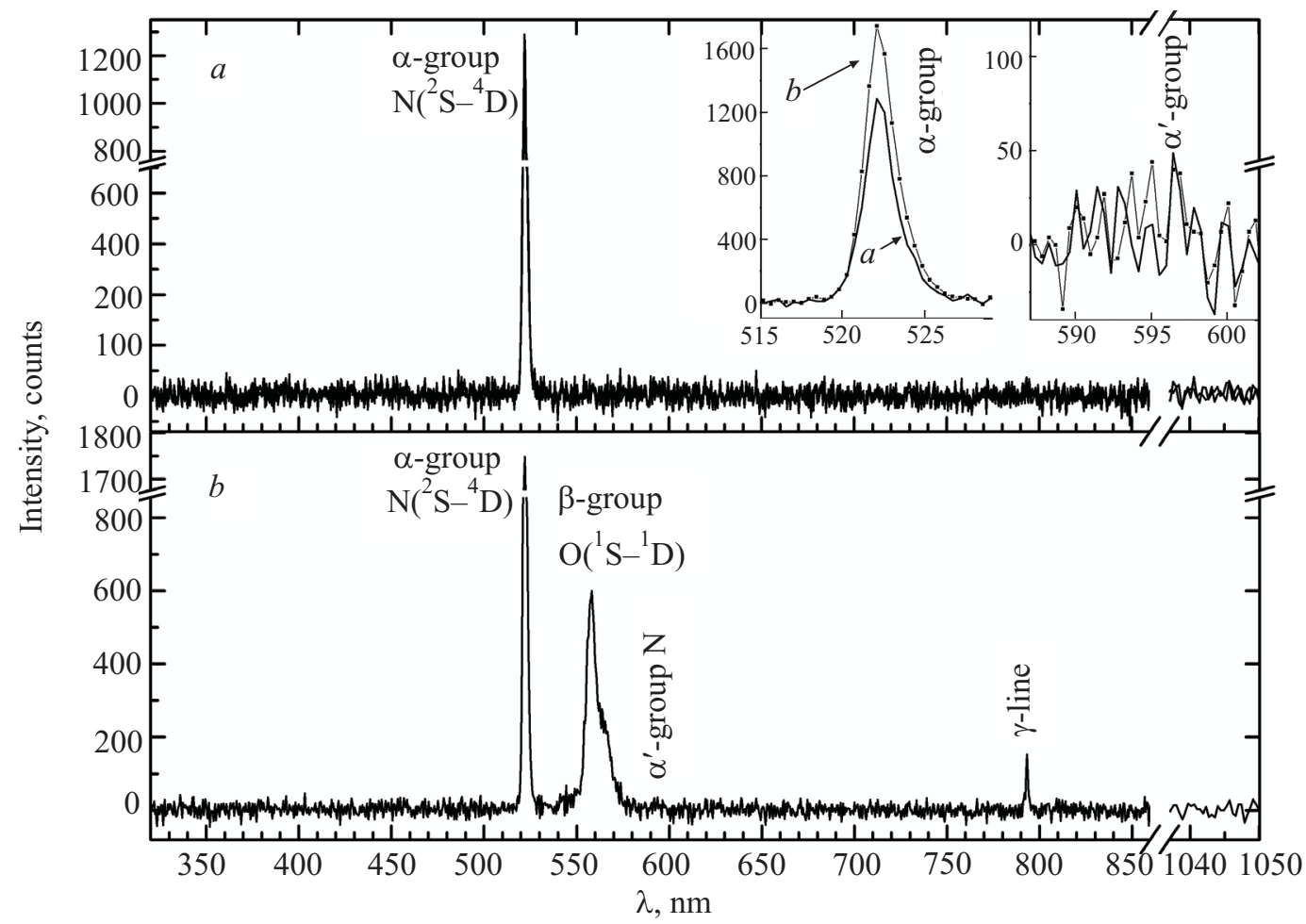

Fig. 8. A comparison of the thermoluminescence spectra detected at the beginning $(a)$ and the end $(b)$ of the "delayed" sample destruction. The corresponding spectra of $\alpha$ - and $\alpha^{\prime}$-groups are shown in insets.

important differences in the thermoluminescence dynamics and $\alpha$-group spectra were observed. Firstly, there was relatively weak $\alpha$-group emission during the time interval between the luminescence maxima. It was found that the shapes of the $\alpha$-group spectra during sample destruction were almost identical. This is indicated in Fig. 7, which shows a sequence of $\alpha$-group spectra detected at different times during the "delayed" warming of the sample. The intensity maxima of all the spectra are located at $522 \mathrm{~nm}$.

The two most intense spectra detected at the beginning and the end of the "delayed" warm-up of the sample is shown in Figs. 8, $a$ and 8,b. The spectra of the $\alpha$ - and $\alpha^{\prime}$-groups are compared separately in the insets of Fig. 8. One can see in the insets that the position of maxima coincide for both the $\alpha$ - and $\alpha^{\prime}$-groups. The luminescence intensity was much lower compared to those observed during "fast" warming. A rough estimation of the ratio $I_{\alpha} / I_{\alpha^{\prime}} \sim 30$ was made.

\subsection{Thermoluminescence spectra of samples condensed from the gas mixture $\left[\mathrm{N}_{2}\right]:[\mathrm{Kr}]:[\mathrm{He}]=1: 50: 10000$}

The integrated spectrum (along the whole jet length) of the gas mixture of composition $\left[\mathrm{N}_{2}\right]:[\mathrm{Kr}]:[\mathrm{He}]=1: 50: 10000$ after passing through the $\mathrm{rf}$ discharge region is given in Fig. 9. The main features of the spectrum are the intense lines of $\mathrm{Kr}$ and $\mathrm{He}$ atoms. The intensities of $\alpha$ - and $\beta$-groups are weak due to the lower impurity content in the gas mixture used $(1 / 200$ in contrast to $1 / 25$ for the case of the neon-helium gas mixtures). This also indicates that the onset of clustering of the impurity particles occurs in a region very close to the HeII surface in the beaker [24]. The thermoluminescence spectra detected during warm-up of the sample are given in Fig. 10. The spectra were similar each to other and only the emission intensity increased during warm-up of the sample.

Each of the spectra consists of an intense $\beta$-group, weaker $M$-bands of NO molecules, corresponding to the transitions $a^{4} \Pi\left(v^{\prime \prime}=0\right) \rightarrow X^{2} \Pi\left(v^{\prime}=4-11\right)$, and a very weak $\alpha$-group (see Fig. 11). The positions, identifications, and integrals of the features observed are listed in Table 1. In addition, the positions of the M-bands observed in the krypton matrix are listed in the Table 1 for comparison [28].

\section{Discussion}

\subsection{Explanation of two maxima observed in emission of the a-group during destruction of IHCs, containing stabilized free radicals}

Two maxima of the $\alpha$-group intensity were recorded in the thermoluminescence of the IHC samples in these experiments as shown in Figs. 3 and 6. Similar behavior was recorded in earlier investigations of $\mathrm{N}-\mathrm{N}_{2}-\mathrm{Kr}-\mathrm{He}$ and $\mathrm{N}-$ $\mathrm{N}_{2}-\mathrm{He}$ samples [9,21]. IHCs are porous materials, formed by a collection of impurity nanoclusters. The pores of the condensates are filled with superfluid helium. For the initiation of sample destruction liquid helium should be removed from the sample cell. During removal of liquid helium from the pores, the sample volume was reduced 


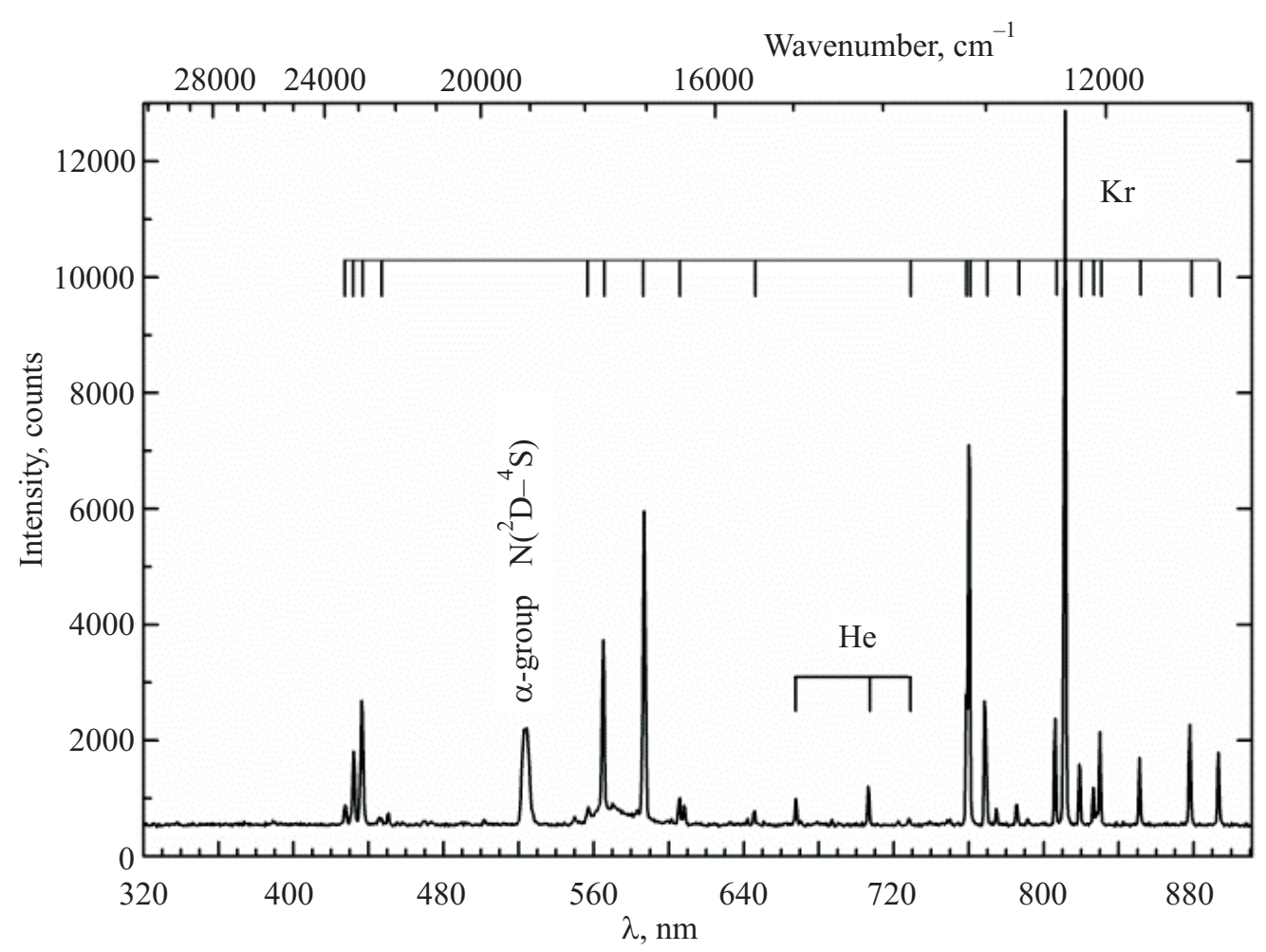

Fig. 9. The integrated luminescence spectrum of the gas jet (with composition $\left[\mathrm{N}_{2}\right]:[\mathrm{Kr}]:[\mathrm{He}]=1: 50: 10000$ ) after passing the rf discharge region during sample accumulation.

substantially as a result of the collapse of the large pores, which led to new contacts between the cluster surfaces, where most of the stabilized atoms were residing. As a consequence, atom recombination was initiated and the first maxima of thermoluminescence appeared. At the next stage, helium evaporation occurred from the smaller pores of the sample and from the surfaces of nanoclusters. This evaporative cooling reduces the sample temperature and suppresses the recombination of atoms. The intensity of emission decreases during sample cooling. The sample cooling continues up to the point when the isolating solid layers of helium are destroyed and the recombination of

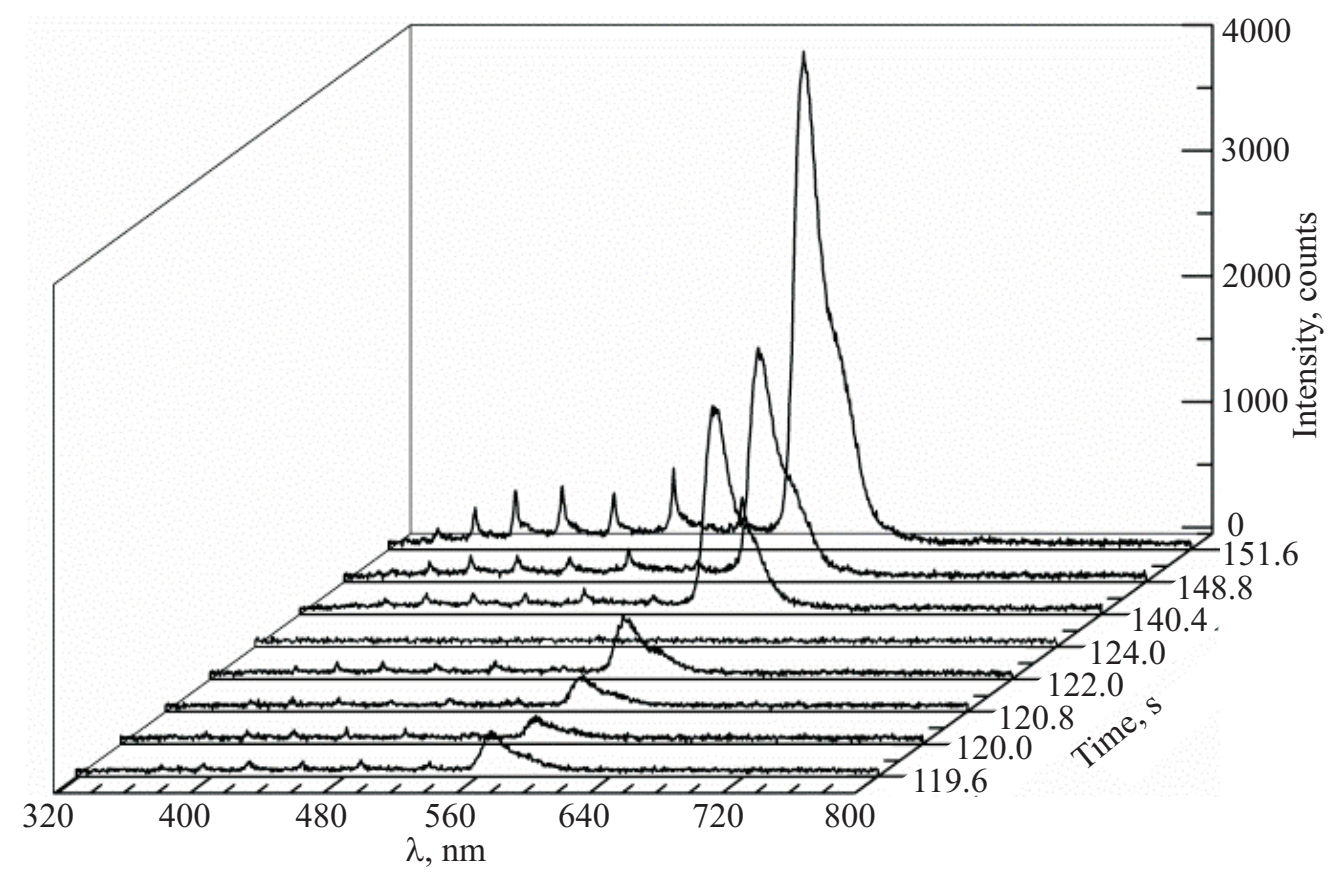

Fig. 10. A sequence of the flashes detected during destruction of the sample condensed from the gas mixture $\left[\mathrm{N}_{2}\right]:[\mathrm{Kr}]:[\mathrm{He}]=$ $=1: 50: 10000$. 


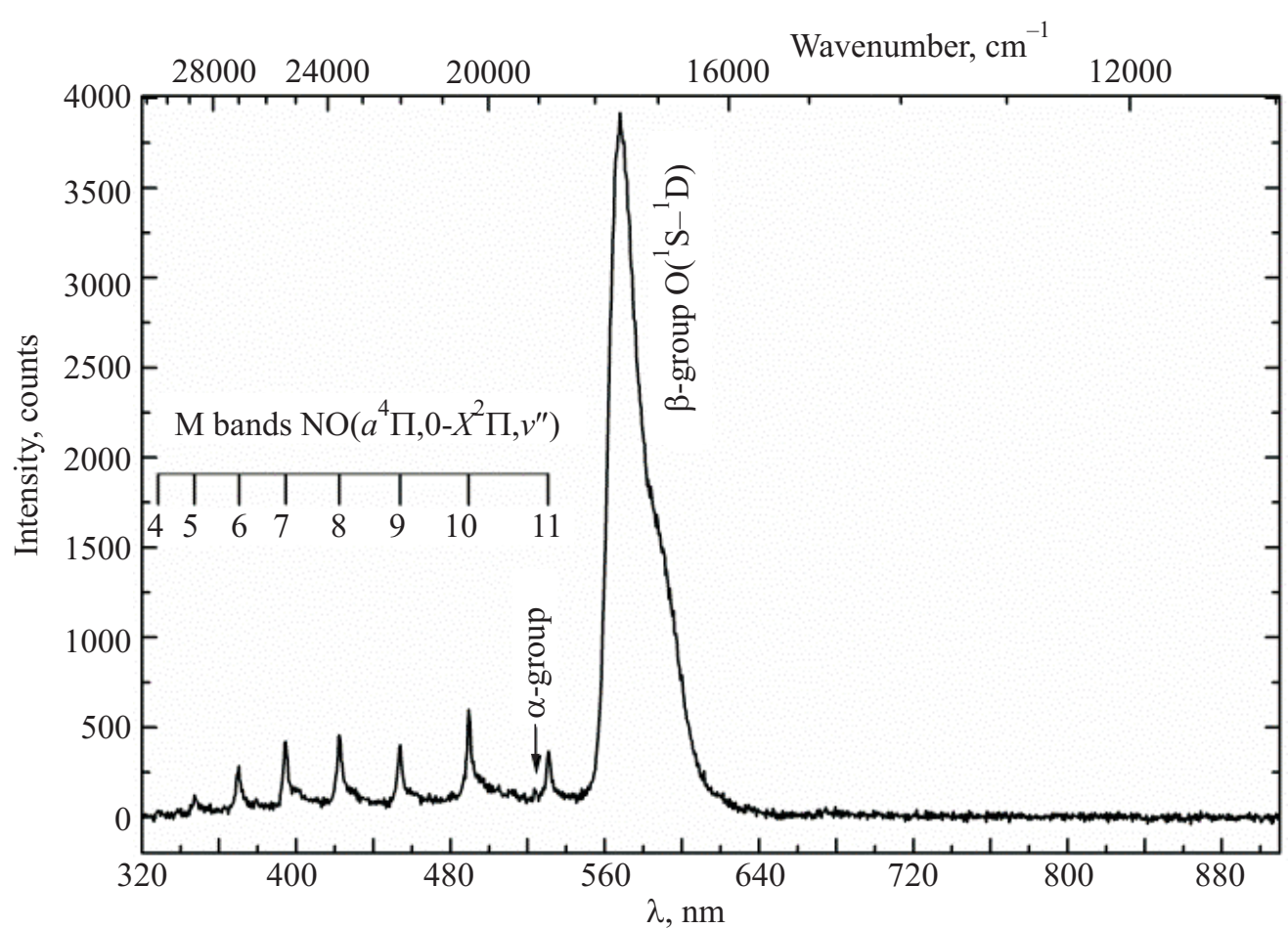

Fig. 11. The spectrum of the most intense flash during destruction of the sample condensed from the gas mixture $\left[\mathrm{N}_{2}\right]:[\mathrm{Kr}]:[\mathrm{He}]=$ $=1: 50: 10000$.

stabilized atoms starts again. At this stage the recombination is more intense. The temperature of the sample grows faster, and the clusters coalesce, forming a bulk solid matrix. Recombination of the stabilized free radicals produces excited molecules. The excitation energy of molecules may be efficiently transferred through the matrix to the stabilized nitrogen and oxygen atoms that survived during cluster coalescence. The intensity of atom luminescence thus increases, giving the second maxima in the thermoluminescence. The intensity of the $\beta$-group emission of $\mathrm{O}$ atoms is considerably larger than intensity of $\alpha$-group emissions of $\mathrm{N}$ atoms at this stage because of the much

Table 1. The spectral features of the most intense flash during destruction of the sample condensed from the gas mixture $\left[\mathrm{N}_{2}\right]:[\mathrm{Kr}]:[\mathrm{He}]=1: 50: 10000$

\begin{tabular}{c|c|c|c|c}
\hline \hline No & $\begin{array}{c}\text { Line } \\
\text { posi- } \\
\text { tion, } \\
\mathrm{nm}\end{array}$ & $\begin{array}{c}\text { The } \\
\text { area } \\
\text { under } \\
\text { the line }\end{array}$ & $\begin{array}{c}\text { Position } \\
\text { observed in } \\
\text { Kr matrix } \\
{[28], \mathrm{nm}}\end{array}$ & Line origin \\
\hline \hline 1 & 328.1 & & 327.3 & NO M-band 0->4 \\
2 & 347.8 & & 347.2 & NO M-band 0->5 \\
3 & 370.2 & 1967 & 369.4 & NO M-band 0->6 \\
4 & 394.5 & 2820 & 394.1 & NO M-band 0->7 \\
5 & 422.1 & 3075 & 421.9 & NO M-band 0->8 \\
6 & 453.9 & 2780 & 453.4 & NO M-band 0->9 \\
7 & 489.4 & 3846 & 489.3 & NO M-band 0->10 \\
8 & 523.4 & & & N $\left({ }^{2} \mathrm{D}-{ }^{4} \mathrm{~S}\right)$ \\
9 & 530.7 & 2655 & 530.7 & NO M-band 0->11 \\
10 & 567.7 & 103480 & \multicolumn{3}{c}{$\left(^{1}{ }^{1} \mathrm{D}\right)$} \\
\hline \hline
\end{tabular}

higher $\left(\sim 10^{7}\right.$ times $)$ probability of the $\mathrm{O}\left({ }^{1} \mathrm{~S}-{ }^{1} \mathrm{D}\right)$ transition as compared with the $\mathrm{N}\left({ }^{2} \mathrm{D}-{ }^{4} \mathrm{~S}\right)$ transition. Although the concentration of stabilized $\mathrm{N}$ atoms in this final solid matrix is two or three orders of magnitude larger than that of the $\mathrm{O}$ atoms, the significantly larger transition probability of $\mathrm{O}$ atoms leads to a stronger emission from the $\mathrm{O}$ atoms.

For samples with very high concentrations of stabilized atoms the final stage leads to complete sublimation of the sample. It is interesting that both samples under investigation, neon-helium and krypton-helium, were destroyed at temperatures below $14 \mathrm{~K}$. We have not presented the thermograms during the process of sample warming because only one thermometer, which was placed inside the sample under investigation, was employed. Impurity-helium samples with high porosity are efficient thermal isolators even when they immersed inside a volume of superfluid helium [29]. That is why the temperature recorded by a thermometer inside the sample during the process of warming might be a few degrees lower than that placed above the surface of the sample. The difference between temperatures inside and outside of the samples was observed when we used two thermometers in earlier experiments. One of thermometers was placed inside the sample and another was outside the sample, close to the surface [9]. The recorded temperatures of two thermometers became equal at the moment of complete destruction of the sample. Since we were limited to one thermometer inside the sample, we could only determine the temperature of sample destruction. The precise dependence on temperature of the intensity and the shape of the thermoluminescence spectra is dif- 
ficult to obtain. The process of warming up the sample initiates energy releases due to spontaneous atom recombination and, as a consequence, the recorded flashes correspond to those parts of the sample where the local temperature was highest.

It is worth noting the destruction temperatures of the samples under study are close to the ones at which thermoluminescence and exoelectron emission were initiated in films of solid $\mathrm{Ne}, \mathrm{Ar}, \mathrm{Kr}, \mathrm{Xe}$ [30,31], and $\mathrm{N}_{2}$ [32]. The processes were caused by ions trapped in cryofilms: electrons began to escape from the traps at $8-10 \mathrm{~K}$ followed by exoelectron emission and ion recombination, which in turn forced the film warm-up, luminescence in the UV and visual ranges, and ejection of "hot" atoms from the film surface. We cannot exclude the presence of ions trapped by growing impurity clusters in the gas jet, but none were observed in our experiments. We now believe the main trigger for IHC sample destruction is evaporation of helium atoms from the impurity nanocluster surfaces.

\subsection{Dynamics of $\alpha$-group structure changes during destruction of nitrogen-neon-helium sample}

Studies of changes in the thermoluminescence spectra during the destruction of IHCs containing stabilized $\mathrm{N}$ and $\mathrm{O}$ atoms allow us to draw some conclusions regarding the possible structure of nanoclusters forming the IHCs as well as to characterize the trapping sites of stabilized atoms. Figure 12 shows $\alpha$-group spectra recorded under different conditions, such as during bombardment of a solid molecular nitrogen matrix by low energy and high energy electrons, as well as during the formation of a nitrogen-helium condensate. It is known that the spectrum of the $\alpha$-group of $\mathrm{N}$ atoms contains three main maxima at wavelengths $521 \mathrm{~nm}, 522 \mathrm{~nm}$, and $523 \mathrm{~nm}[33,34]$. Each of these maxima corresponds to emission by $\mathrm{N}$ atoms trapped in specific locations in the $\mathrm{N}_{2}$ matrix. $\mathrm{N}$ atoms in substitutional sites of N matrix emit light at $\lambda=523 \mathrm{~nm}$. This emission is initiated by matrix phonons. Emission at $\lambda=522 \mathrm{~nm}$ corresponds to the zero phonon transition of $\mathrm{N}$ atoms induced by the crystalline field of $\mathrm{N}_{2}$ matrix. The emission at $\lambda=521$ $\mathrm{nm}$ was explained initially as an anti-Stokes transition of $\mathrm{N}$ atoms, which was induced by lattice phonons [33]. This emission was later assigned to $\mathrm{N}$ atoms residing on the surface of the nitrogen matrix [34]. The maximum at $\lambda=521 \mathrm{~nm}$ was also prevalent in the $\alpha$-group spectra recorded during formation of an IHC, which was composed of a collection of $\mathrm{N}_{2}$ nanoclusters and was characterized by a high surface to volume ratio. This observation supports the latter interpretation of the emission at $\lambda=521 \mathrm{~nm}$.

During preparation of $\mathrm{N}-\mathrm{N}_{2}-\mathrm{Ne}-\mathrm{He}$ condensates, the luminescence maximum was observed at $\lambda=520 \mathrm{~nm}$ [8]. In this case the decay time of the intensity was increased compared to that of $\mathrm{N}-\mathrm{N}_{2}-\mathrm{He}$ condensate. The time for the decay of the luminescence intensity for $\mathrm{N}$ atoms in an $\mathrm{N}_{2}$ matrix is equal to $15-30 \mathrm{~s}$, but for the case of $\mathrm{N}$ atom lu-

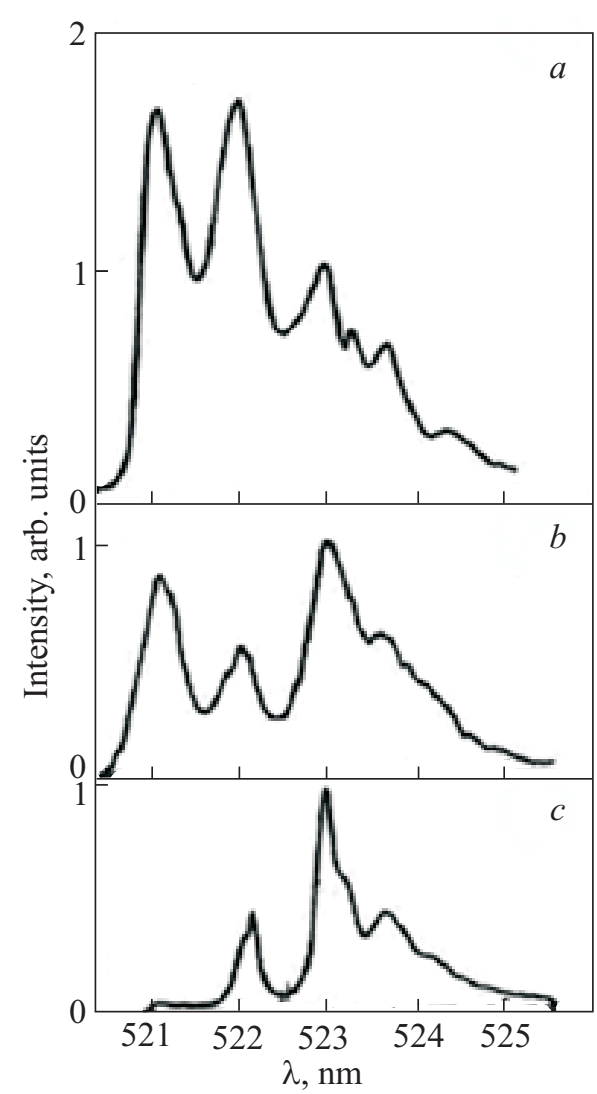

Fig. 12. $\alpha$-group spectra: during the nitrogen-helium sample preparation $(a)$; from solid molecular nitrogen irradiated by low-energy electrons $(E=200 \mathrm{eV})$ [34] (b); from solid molecular nitrogen irradiated by high-energy electrons $(E=10 \mathrm{keV})[33](c)$.

minescence in the Ne matrix, the decay time increases to $\sim 360 \mathrm{~s}[8,22]$. Additional information about the surroundings of emitting $\mathrm{N}$ and $\mathrm{O}$ atoms might be obtained from the dynamics of spectral changes during different regimes of sample destruction.

During "fast" warm up of the $\mathrm{N}-\mathrm{N}_{2}-\mathrm{Ne}-\mathrm{He}$ samples, an $\alpha$-group spectrum transformation had been detected as was shown in Fig. 4. At the early stage of sample warming, the $\alpha$-group spectra is similar to that of $\mathrm{N}$ atoms in a Ne matrix $\left(\lambda_{\max } \sim 520 \mathrm{~nm}\right)$. At the final stage of sample warming, the maximum of luminescence shifts to the wavelength $\lambda \sim 522 \mathrm{~nm}$, which correspond to the luminescence of $\mathrm{N}$ atoms in $\mathrm{N}_{2}$ molecular matrix. Along with the luminescence at $\lambda \sim 522 \mathrm{~nm}$, an intense $\beta$-group luminescence that corresponds to $\mathrm{O}$ atoms in an $\mathrm{N}_{2}$ matrix was detected.

During the "delayed" warming, the sample kept emitting radiation for a long time (up to $1800 \mathrm{~s}$ ) after preparation at low temperature and before the beginning of the rapid warming that leads to sample destruction. During delay time the intensity of the luminescence of the atoms excited in the discharge zone and trapped in the sample eventually became weaker than the sensitivity threshold of the spectrometer. 
By comparing the thermoluminescence spectra of different samples prepared from the gas mixture $\left[\mathrm{N}_{2}\right]:[\mathrm{Ne}]:[\mathrm{He}]=$ $=1: 20: 500$, no changes were found in the shape of the $\alpha-$ group during the destruction of the samples which were kept at low temperatures for over $300 \mathrm{~s}$ before starting the warm-up. Thus in the case of "delayed" sample warming, only the luminescence of the atoms excited directly in the sample during its destruction could be recorded. At the same time the spectrum of the $\alpha$-group both at the beginning and at the end of destruction corresponds to $\mathrm{N}$ atoms in an $\mathrm{N}_{2}$ matrix and no transformation of the $\alpha$-group spectra was detected. At the final stages of destruction the intense luminescence of the $\beta$-group was detected, in agreement with the case of the "fast" warming.

The detected features of the spectra lead to the conclusion that during the accumulation of $\mathrm{N}-\mathrm{N}_{2}-\mathrm{Ne}-\mathrm{He}$ samples a substantial fraction of emitting $\mathrm{N}\left({ }^{2} \mathrm{D}\right)$ atoms was surrounded mostly by $\mathrm{Ne}$ atoms, while during the destruction of these samples, the $\mathrm{N}$ and $\mathrm{O}$ atoms surrounded by $\mathrm{N}_{2}$ molecules emitted light. To explain these observations we need to use some known facts on the formation of clusters which formed the impurity-helium samples. While the helium gas jet containing impurity atoms and molecules $(\mathrm{N}$, $\mathrm{O}, \mathrm{Ne}$ and $\mathrm{N}_{2}$ ) is condensing and the jet cools down, the values of Van der Waals attractive forces between different atoms and molecules indicate that the nanoclusters of $\mathrm{N}_{2}$ should initially be formed, followed by adsorption of $\mathrm{N}$ and $\mathrm{O}$ atoms on the surfaces of the nanoclusters. The layers of $\mathrm{Ne}$ atoms cover the nanoclusters. After formation of the last Ne layer, a layer of solidified helium forms. This corresponds to the existence of a shell structure. In the final step of sample formation inside superfluid helium, these layered nanoclusters freeze together and form a porous structure, in which the pores are filled with superfluid helium.

When we heated the sample after the removal of liquid helium and the sublimation of the solid helium layer from the surface of the impurity clusters, their neon shells are destroyed, initiated by heat from the crystallization of $\mathrm{Ne}$ atoms [35] and heat is released during the recombination of $\mathrm{N}$ atoms stabilized in $\mathrm{Ne}$, which leads to the association of $\mathrm{N}_{2}$ nanoclusters, containing stabilized $\mathrm{N}$ and $\mathrm{O}$ atoms. Since the concentration of nitrogen atoms is significantly higher than the concentration of oxygen atoms, the main source of energy released during destruction of these samples is the recombination of nitrogen atoms:

$$
\mathrm{N}\left({ }^{4} \mathrm{~S}\right)+\mathrm{N}\left({ }^{4} \mathrm{~S}\right) \rightarrow \mathrm{N}_{2}\left(\mathrm{~A}^{3} \Sigma_{u}\right)
$$

Electronic excitation of the nitrogen molecules can easily migrate through the newly formed $\mathrm{N}_{2}$ matrix until it is transferred to the stabilized $\mathrm{N}$ and $\mathrm{O}$ atoms [33]:

$$
\begin{aligned}
& \mathrm{N}_{2}\left(\mathrm{~A}^{3} \Sigma_{u}{ }^{+}\right)+\mathrm{N}\left({ }^{4} \mathrm{~S}\right) \rightarrow \mathrm{N}\left({ }^{2} \mathrm{D}\right)+\mathrm{N}_{2}\left(\mathrm{X}^{1} \Sigma_{g}{ }^{+}\right), \\
& \mathrm{N}_{2}\left(\mathrm{~A}^{3} \Sigma_{u}{ }^{+}\right)+\mathrm{O}\left({ }^{3} \mathrm{P}\right) \rightarrow \mathrm{O}\left({ }^{1} \mathrm{~S}\right)+\mathrm{N}_{2}\left(\mathrm{X}^{1} \Sigma_{g}{ }^{+}\right) .
\end{aligned}
$$

The luminescence of the excited atoms formed in this way determines the dynamics of the main features of the sample luminescence during their destruction as indicated below:

$$
\begin{aligned}
& \mathrm{N}\left({ }^{2} \mathrm{D}\right) \rightarrow \mathrm{N}\left({ }^{4} \mathrm{~S}\right)+\alpha \text {-group, } \\
& \mathrm{O}\left({ }^{1} \mathrm{~S}\right) \rightarrow \mathrm{O}\left({ }^{3} \mathrm{P}\right)+\beta \text {-group. }
\end{aligned}
$$

\section{3. $\alpha^{\prime}$ - and $\delta^{\prime \prime}$-group spectra of the nitrogen atom and the $\beta^{\prime}$-and $\beta^{\prime \prime}$-group spectra of oxygen atom during the destruction of nitrogen-neon-helium samples.}

The above described model of the shell structure of the clusters that comprise the IHC samples is supported by data from the $\alpha^{\prime}$ - and $\delta^{\prime \prime}$-groups of nitrogen atoms, and the $\beta^{\prime}$ - and $\beta^{\prime \prime}$-groups of oxygen atoms. Dressler and Oehler [33] showed that the following processes are responsible for the luminescence of the $\alpha^{\prime}$-, $\beta^{\prime}$-, $\beta^{\prime \prime}$ - and $\delta^{\prime \prime}$-groups:

$$
\begin{aligned}
\mathrm{N}\left({ }^{2} \mathrm{D}\right) & +\mathrm{N}_{2}\left(\mathrm{X}^{1} \Sigma_{g}^{+}, v^{\prime \prime}=0\right) \rightarrow \mathrm{N}\left({ }^{4} \mathrm{~S}\right)+ \\
& +\mathrm{N}_{2}\left(\mathrm{X}^{1} \Sigma_{g}^{+}, v^{\prime \prime}=1\right)+\alpha^{\prime} ; \\
\mathrm{O}\left({ }^{1} \mathrm{~S}\right) & +\mathrm{N}_{2}\left(\mathrm{X}^{1} \Sigma_{g}^{+}, v^{\prime \prime}=0\right) \rightarrow \mathrm{O}\left({ }^{3} \mathrm{P}\right)+ \\
& +\mathrm{N}_{2}\left(\mathrm{X}^{1} \Sigma_{g}^{+}, v^{\prime \prime}=1\right)+\beta^{\prime} ; \\
\mathrm{O}\left({ }^{1} \mathrm{~S}\right) & +\mathrm{N}_{2}\left(\mathrm{X}^{1} \Sigma_{g}^{+}, v^{\prime \prime}=1\right) \rightarrow \mathrm{O}\left({ }^{3} \mathrm{P}\right)+ \\
& +\mathrm{N}_{2}\left(\mathrm{X}^{1} \Sigma_{g}^{+}, v^{\prime \prime}=0\right)+\beta^{\prime \prime} ; \\
\mathrm{N}\left({ }^{2} \mathrm{P}\right) & +\mathrm{N}_{2}\left(\mathrm{X}^{1} \Sigma_{g}^{+}, v^{\prime \prime}=1\right) \rightarrow \mathrm{N}\left({ }^{2} \mathrm{D}\right)+ \\
& +\mathrm{N}_{2}\left(\mathrm{X}^{1} \Sigma_{g}^{+}, v^{\prime \prime}=0\right)+\delta^{\prime \prime} .
\end{aligned}
$$

Thus the presence of the $\alpha^{\prime}$ - and $\delta^{\prime \prime}$-groups of nitrogen atoms, and the $\beta^{\prime}$ - and $\beta^{\prime \prime}$-groups of the oxygen atoms in the spectra indicates the presence of $\mathrm{N}_{2}$ molecules in the nearest (first) coordination sphere of the excited $\mathrm{N}$ and $\mathrm{O}$ atoms.

Within the molecular matrix, $\mathrm{N}$ atoms in substitutional sites have 12 neighboring molecules of $\mathrm{N}_{2}$, and the ratio of the intensities of $\alpha$ - and $\alpha^{\prime}$-groups, $I_{\alpha} / I_{\alpha^{\prime}}$, is of order 10 [33]. The position of the $\alpha$-group maximum $(\lambda \sim 520 \mathrm{~nm})$ at the beginning of the warm up (see Figs. 4 and 5,a) indicates that $\mathrm{N}$ atoms are surrounded by $\mathrm{Ne}$ atoms, while the presence of the $\alpha^{\prime}$-group in the spectrum means that $\mathrm{N}_{2}$ molecules are also present in the surroundings of the same $\mathrm{N}$ atoms. We can therefore conclude that the nitrogen atoms located between the layers of molecular nitrogen and atomic neon are responsible for the luminescence shown in Fig. 5,a. The intensity ratio $I_{\alpha} / I_{\alpha^{\prime}}$ for the spectrum is equal to 570 , which means that a nitrogen atom is surrounded by only a few $\mathrm{N}_{2}$ molecules. At the final stage of the warm up this ratio increases to 80 , and this confirms the fact that after the nanoclusters combine, the emitting nitrogen atoms have mainly $\mathrm{N}_{2}$ neighbors.

\subsection{Discussion of the results of the nitrogen-krypton- helium sample studies}

The luminescence spectra during the destruction of $\mathrm{N}-\mathrm{N}_{2}-\mathrm{Kr}-\mathrm{He}$ samples differ significantly from the spectra that accompany the destruction of the $\mathrm{N}-\mathrm{N}_{2}-\mathrm{Ne}-\mathrm{He}$ samples. In $\mathrm{N}-\mathrm{N}_{2}-\mathrm{Ne}-\mathrm{He}$ sample spectra, only intense 
bands of $\mathrm{O}$ and $\mathrm{N}$ atoms were detected, while during the $\mathrm{N}-\mathrm{N}_{2}-\mathrm{Kr}-\mathrm{He}$ sample destruction not only bands of $\mathrm{O}$ and $\mathrm{N}$ atoms were present, but also bands of $\mathrm{NO}$ molecules were recorded. This dramatic difference in the spectra of $\mathrm{N}-\mathrm{N}_{2}-\mathrm{Kr}-\mathrm{He}$ samples, as compared with the $\mathrm{N}-\mathrm{N}_{2}-\mathrm{Ne}-\mathrm{He}$ results, can be explained by the difference in the shell structure of the nanoclusters formed. In the case of condensation of nitrogen-krypton gas mixtures during the cooling of the gas jet, at first krypton nanoclusters are formed. When the temperatures get lower, atoms and molecules of nitrogen and oxygen atoms are adsorbed on the surface of these krypton nanoclusters. Finally, helium atoms are adsorbed on the surface of the impurity clusters. When the original ratio of the gas mixture is $\left[\mathrm{N}_{2}\right]:[\mathrm{Kr}]:[\mathrm{He}]=$ $=1: 50: 10000$ and the average number of $\mathrm{Kr}$ atoms per cluster is $\sim 2000$ [3], the average number of nitrogen atoms in a cluster can be estimated as equal to $\sim 80$. This number of atoms is not enough to form a monolayer (even if we completely exclude recombination between nitrogen atoms). The warming of the nitrogen-krypton-helium sample initiates an association of nanoclusters, and the recombination of $\mathrm{O}$ and $\mathrm{N}$ atoms leads to the formation of excited $\mathrm{NO}$ and $\mathrm{N}_{2}$ molecules. In this case, as in [19], for the thermoluminescence spectra we detected the M-bands of the NO molecules, along with the $\alpha$-group of $\mathrm{N}$ atoms and the $\beta$-group of $\mathrm{O}$ atoms, despite the numerical dominance by more than an order of magnitude of the excited $\mathrm{N}_{2}$ molecules. The most obvious channel for the nonradiative relaxation of $\mathrm{N}_{2}\left(\mathrm{~A}^{3} \Sigma_{u}^{+}\right)$molecules is the excitation of the neighboring atoms of $\mathrm{N}\left({ }^{4} \mathrm{~S}\right), \mathrm{O}\left({ }^{3} \mathrm{P}\right)[33]$ and molecules of $\mathrm{NO}\left(\mathrm{X}^{2} \Pi\right)$. The processes of excitation transfer from $\mathrm{N}_{2}\left(\mathrm{~A}^{3} \Sigma_{u}^{+}\right)$to the $\mathrm{NO}\left(\mathrm{X}^{2} \Pi\right)$ molecules were investigated in Ref. 36.

The adsorption of nitrogen atoms on the surface of krypton nanoclusters leads to a more effective stabilization of atoms. A similar effect for increased efficiency of atom stabilization has been detected in hydrogen-krypton samples and deuterium-krypton samples, leading to recordbreaking concentrations of stabilized hydrogen and deuterium atoms $[5,6,37]$.

\section{Conclusions}

1. The recorded changes of the position of the maximum peak in the $\alpha$-group of the nitrogen atom spectrum during the destruction of nitrogen-neon-helium samples show that the number of nitrogen molecules surrounding the emitting nitrogen atoms is increasing during the process of destruction of the sample. This is also confirmed by a decrease in the intensity ratio of $\alpha$-and $\alpha^{\prime}$-groups, $I_{\alpha} / I_{\alpha^{\prime}}$, from 570 at the beginning of the sample destruction to 80 in the end.

2. The IHC samples of different compositions showed different relaxation dynamics for the energy released as a result of recombination of stabilized radicals. During the warming of nitrogen-krypton-helium samples, the structure of the thermoluminescence spectrum does not change.
On the other hand, the thermoluminescence spectra of nitrogen-neon-helium samples were changed significantly and showed two phases. For the first phase, the $\alpha$-group of the nitrogen atoms in the mixed nitrogen-neon surroundings dominates the spectra. In the second phase, we observe radiative processes similar to those observed in a molecular nitrogen matrix, with dominance of the $\beta$-group of oxygen atoms in the spectra.

3. Studies of the spectra during the destruction of impurty-helium condensates formed by impurities with different freezing temperatures made it possible to confirm the "shell" model for nanoclusters formed in gas jet cooled by helium vapors. As was suggested in [38], during the cooling of the jet prior to its injection into superfluid helium, nanoclusters of impurity particles with a higher freezing temperature are formed at first, and then impurity particles with a lower freezing temperature adsorb on the surface of the these nanoclusters. For example, in the supersonic jets containing rare gas atoms, clusters with multishell structures are formed [39-42]. In the case of nitrogen-neon samples, initially nanoclusters of molecular nitrogen which have the melting temperature close to that of molecular nitrogen matrix $\left(T_{\mathrm{N}_{2}}=63 \mathrm{~K}\right)$ form. Later atoms of nitrogen and neon $\left(T_{\mathrm{Ne}}\right.$ $=24 \mathrm{~K}$ ) are adsorbed on the surface. In nitrogen-krypton sample, the krypton nanoclusters $\left(T_{\mathrm{Kr}}=115 \mathrm{~K}\right)$ initially form and then a layer of molecules and atoms of nitrogen freezes on the surface. The increase in the Van der Waals interaction between the nitrogen atoms and the surface of the krypton nanoclusters in comparison with the interaction with the surface of $\mathrm{N}_{2}$ nanoclusters enhances the efficiency of stabilization of the nitrogen atoms. Thus nitrogenkrypton-helium condensates are very suitable for the creation of systems with a very high density of stored energy. It should be quite promising to carry out systematic ESR studies of nitrogen-krypton condensates formed by condensation of gas mixtures with different relative content of nitrogen and krypton, in order to achieve the maximum concentration of stabilized nitrogen atoms.

The study was supported by grants № 010366-01372009 Norman Hackerman Advanced Research Program, RFBR № 11-02-92500-CRDF-E_a and CRDF № RUP17025-CG-11, federal contract 11.519.11.6021 with Russian Federation Ministry of Education and Science.

1. V.V. Khmelenko, H. Kunttu, and D.M. Lee, J. Low Temp. Phys. 148, 1 (2007).

2. V. Kiryukhin, B. Keimer, R.E. Boltnev, V.V. Khmelenko, and E.B. Gordon, Phys. Rev. Lett. 79, 1774 (1997).

3. V. Kiryukhin, E.P. Bernard, V.V. Khmelenko, R.E. Boltnev, N.V. Krainyukova, and D.M. Lee, Phys. Rev. Lett. 98, 195506 (2007).

4. E.P. Bernard, R.E. Boltnev, V.V. Khmelenko, V. Kiryukhin, S.I. Kiselev, and D.M. Lee, Phys. Rev. B69, 104201 (2004).

5. R.E. Boltnev, V.V. Khmelenko, and D.M. Lee, Fiz. Nizk. Temp. 36, 484 (2010) [Low Temp. Phys. 36, 382 (2010)]. 
6. R.E. Boltnev, E.P. Bernard, J. Jarvinen, I.N. Krushinskaya, V.V. Khmelenko, and D.M. Lee, J. Low Temp. Phys. 158, 468 (2010).

7. E.P. Bernard, R.E. Boltnev, V.V. Khmelenko, and D.M. Lee, J. Low Temp. Phys. 134, 199 (2004).

8. R.E. Boltnev, E.B. Gordon, V.V. Khmelenko, M.V. Martynenko, A.A. Pelmenev, E.A. Popov, and A.F. Shestakov, J. Chim. Phys. 92, 362 (1995).

9. R.E. Boltnev, E.B. Gordon, I.N. Krushinskaya, M.V. Martynenko, A.A. Pelmenev, E.A. Popov, V.V. Khmelenko, and A.F. Shestakov, Fiz. Nizk. Temp. 23, 753 (1997) [Low Temp. Phys. 23, 567 (1997)].

10. A.M. Bass and H.P. Broida, Formation and Trapping of Free Radicals, Academic Press, New York (1960).

11. S.I. Kiselev, V.V. Khmelenko, D.M. Lee, V. Kiryukhin, R.E. Boltnev, E.B. Gordon, and B. Keimer. Phys. Rev. B65, 024517 (2001).

12. S.I. Kiselev, V.V. Khmelenko, D.M. Lee, V. Kiryukhin, R.E. Boltnev, E.B. Gordon, and B. Keimer, J. Low Temp. Phys. 126, 235 (2002).

13. L. Vegard, Nature 113, 716 (1924).

14. L. Vegard, Nature 114, 357 (1924).

15. J.C. McLennan, H.J.C. Ireton, and E.W. Samson, Proc. R. Soc. London 120A, 303 (1928).

16. A.M. Bass and H.P. Broida, Phys. Rev. 101, 1740 (1956).

17. H.P. Broida and M. Peyron, J. Chem. Phys. 32, 1068 (1960).

18. M. Peyron and H.P. Broida, J. Chem. Phys. 30, 139 (1959).

19. J. Eloranta, K. Vasconen, H. Häkkänen, T. Kiljunen, and H. Kunttu, J. Chem. Phys. 109, 7784 (1998).

20. A.N. Ponomaryov, E.V. Savchenko, G.B. Gumenchuk, I.V. Khizhniy, M. Frankowski, and V.E. Bondybey, Fiz. Nizk. Temp. 33, 705 (2007) [Low Temp. Phys. 33, 532 (2007)].

21. E.B. Gordon, L.P. Mezhov-Deglin, O.F. Pugachev, and V.V. Khmelenko. JETP 46, 502 (1977).

22. R.E. Boltnev, E.B. Gordon, V.V. Khmelenko, I.N. Krushinskaya, M.V. Martynenko, A.A. Pelmenev, E.A. Popov, and A.F. Shestakov, Chem. Phys. 189, 367 (1994).

23. R.E. Boltnev, I.N. Krushinskaya, A.A. Pelmenev, D.Yu. Stolyarov, and V.V. Khmelenko, Chem. Phys. Lett. 305, 217 (1999).

24. E.A. Popov, J. Eloranta, J. Ahokas, and H. Kunttu, Fiz. Nizk. Temp. 29, 684 (2003) [Low Temp. Phys. 29, 510 (2003)].
25. E.A. Popov, J. Ahokas, J. Eloranta, and H. Kunttu, J. Low Temp. Phys. 139, 557 (2005).

26. R.E. Boltnev, I.N. Krushinskaya, A.A. Pelmenev, E.A. Popov, D.Yu. Stolyarov, and V.V. Khmelenko, Fiz. Nizk. Temp. 31, 723 (2005) [Low Temp. Phys. 31, 547 (2005)].

27. E.B. Gordon, L.P. Mezhov-Deglin, and O.F. Pugachev. JETP Lett. 19, 103 (1974).

28. R.P. Frosch and G.W. Robinson, J. Chem. Phys. 41, 367 (1964).

29. A.A. Pelmenev, E.A. Popov, E.B. Gordon, J. Low Temp. Phys. 119, 367(2000).

30. E.V. Savchenko, I.V. Khyzhniy, S.A. Uyutnov, G.B. Gumenchuk, A.N. Ponomaryov, and V.E. Bondybey, Fiz. Nizk. Temp. 35, 520 (2009) [Low Temp. Phys. 35, 409 (2009)].

31. E.V. Savchenko, I.V. Khyzhniy, S.A. Uyutnov, G.B. Gumenchuk, and A.N. Ponomaryov, NIM B267, 1733 (2009).

32. I. Khyzhniy, E. Savchenko, S. Uyutnov, G. Gumenchuk, A. Ponomaryov, and V. Bondybey, Rad. Measurements 45, 353 (2010).

33. O. Oehler, D.A. Smith, and K. Dressler, J. Chem. Phys. 66, 2097 (1977).

34. R.S. Sayer, R.H. Prince, and W.W. Duley, Proc. R. Soc. London 365A, 235 (1979).

35. E.B. Gordon, V.V. Khmelenko, A.A. Pelmenev, E.A. Popov, O.F. Pugachev, and A.F. Shestakov, Chem. Phys. 170, 411 (1993).

36. L.G. Piper, L.M. Cowles, and W.T. Pawlins, J. Chem. Phys. 85, 3369 (1986).

37. R.E. Boltnev, J. Jarvinen, E.P. Bernard, V.V. Khmelenko, and D.M. Lee, Phys. Rev. B79, 180506(R) (2009).

38. E.B. Gordon, Fiz. Nizk. Temp. 30, 1009 (2004) [Low Temp. Phys. 30, 756 (2004)].

39. O.G. Danylchenko, Yu.S. Doronin, S.I. Kovalenko, and V.N. Samovarov, JETP Lett. 84, 324 (2006).

40. T. Laarmann, K. von Haeften, H. Wabnitz, and T. Möller, J. Chem. Phys. 118, 3043 (2003).

41. A. Kanaev, L. Museur, T. Laarmann, and T. Möller, Fiz. Nizk. Temp. 32, 1426 (2006) [Low Temp. Phys. 32, 1086 (2006)].

42. T. Laarmann, H. Wabnitz, K. von Haeften, and T. Möller, J. Chem. Phys. 128, 014502 (2008). 